\title{
Protamine Based SiRNA-Nanoparticles: Particle Composition Dependant Influences on RNA Interference Efficiency
}

\author{
D. REISCHL ${ }^{1}$, E. JANTSCHER-KRENN ${ }^{1}$, \\ E. BERNHART ${ }^{2}$, W. SATTLER ${ }^{2}$, A. ZIMMER ${ }^{1}$ \\ ${ }^{1}$ Institute of Pharmaceutical Sciences, Department of Pharmaceutical Technology, Karl-Franzens-University \\ Graz, Austria \\ ${ }^{2}$ Institute of Molecular Biology and Biochemistry, Medical University Graz, Austria \\ E-mail: daniela.reischl@uni-graz.at (D. Reischl)
}

Sci Pharm. 2010; 78: 686

doi:10.3797/scipharm.cespt.8.PNM16

The major limitations for the use of small interfering RNA (siRNA) in vivo and in vitro are the relatively high molecular weight, the negative charge, and the susceptibility to nuclease degradation [1]. Therefore it is imperative to use suitable carrier systems to ensure internalization and intracellular separation of the components to subsequently induce RNA interference. The aim of this study was to silence a specific protein expression with a nanoparticulate system by RNA interference and analyze the consequences on tumor cell growth, proliferation and protein expression. Fluorescence microscopy was used for intracellular detection and localization of the components. This study was performed to determine differences between intracellular siRNA delivery after the application of different developed protamine-based nanoparticle systems and their effect on human glioma cells. Therefore two particulate systems composed of i) siRNA and protamine (binary particls) and ii) siRNA, protamine and human serum albumin (ternary particles) were assembled and analysed by size and surface charge before applying on cells. Our study has yielded the following results: fluorescence microscopy showed differences in intracellular particle separation. Binary particles could not be separated after internalization. Protamine-rhodamine B was colocalized with siRNA-FAM dye in the cytoplasm while in case of ternary particles no intracellular protamine signal could be detected. In this case siRNA-FAM was uniformly distributed in the cytoplasm. Furthermore PCR studies showed a protein expression of $76 \%$ for ternary particles and $112 \%$ for the binary system referring to control $(100 \%)$. Proliferation of the cells after transfection was $85 \%$ for ternary particles and $106 \%$ for binary particles. This data verified the necessarity of intracellular separation of siRNA from the nanoparticle complex to induce RNA interference. The authors would like to acknowledge the financial support of the study by FFG, Bridge-program: P810994.

[1] Meade BR, Dowdy SF. Enhancing the cellular uptake of siRNA duplexes following noncovalent packaging with protein transduction domain peptides. Adv Drug Deliv Rev. 2008; 60: 530-536. doi:10.1016/j.addr.2007.10.004 